\title{
Solidão: do patológico ao ontológico
}

\section{Loneliness: from pathological to ontological}

\author{
Soledad: del patológico a lo ontológico
}

Graco Silva Macedocouto*

Universidade Federal do Maranhão - UFMA, São Luís, Maranhão, Brasil

Almir Ferreira da Silva Junior**

Universidade Federal do Maranhão - UFMA, São Luís, Maranhão, Brasil

\begin{abstract}
RESUMO
O objetivo do presente artigo é problematizar o fenômeno da solidão enquanto experiência significativa, no horizonte de nossas relações sociais e afetivas, considerando a legitimidade de sua significação patológica, bem como a primazia de sua ressignificação ontológica. Destaca-se o caráter ontológico da solidão em oposição ao seu horizonte hermenêutico técnicocientífico e biomédico destacando os limites desta abordagem, no tocante à compreensão existencial do fenômeno da solidão. Explicita-se a dimensão ontológica da solidão a partir da fenomenologia de Heidegger ressaltando os fundamentos de uma analítica existencial e a reflexão da solidão enquanto tonalidade afetiva que constituem o ser humano enquanto ser-no-mundo e com-os-outros. Problematiza-se a insuficiência da concepção patológica da solidão para compreendê-la enquanto experiência existencial originária e que se estabelece no horizonte de nossa temporalidade, a partir dos existenciais do ser-com e da tonalidade afetiva da angústia. Ressalta-se a proximidade entre a angústia e a solidão enquanto isolamento existencial, e a importância de se estabelecer junto à angústia e à solidão o que Heidegger denomina de pensamento meditante para a abertura de novos sentidos que permitam o resgate da responsabilização de nossos projetos existenciais, nossa singularização e liberdade.
\end{abstract}

Palavras-chave: solidão, psicologia, analítica existencial, Heidegger.

\begin{abstract}
The purpose of this article is to discuss the phenomenon of loneliness as a significant experience in the horizon of our social and affective relationships considering the legitimacy of their pathological significance, as well as the primacy of their ontological resignification. It highlights the ontological character of loneliness from their technical-scientific and biomedical hermeneutical horizon highlighting the limits of this approach regarding existential understanding of Ioneliness phenomenon. Explains the ontological dimension of loneliness from Heidegger's phenomenology highlighting the foundations of an existential analysis and the reflection of solitude while affective tonality which constitute the human being as being-in- the-world and being-with. Problematizes the failure of pathological loneliness concept to understand it as an existential original experience and that establishes in
\end{abstract}


the horizon of our temporality, from the existential being-with and the anguish affective tone. We emphasize the closeness between anguish and loneliness as existential isolation and the importance of establishing with the anguish and solitude what Heidegger will call meditative thinking for the opening of new meanings that allow the rescue the responsibility of our existential projects, singularity and freedom.

Keywords: Ioneliness, psychology, existential analysis, Heidegger.

\begin{abstract}
RESUMEN
El propósito de este artículo es analizar el fenómeno de la soledad como una experiencia significativa en el horizonte de nuestras relaciones sociales y emocionales teniendo en cuenta la legitimidad de su significado patológico y la primacía ontológica de su reinterpretación. Destaca el carácter ontológico de la soledad desde su horizonte hermenéutico técnico-científico y biomédico. Explica la dimensión ontológica de la soledad de la fenomenología de Heidegger destacando las bases de un análisis y reflexión de la soledad existencial aunque la tonalidad afectiva que conforman al ser humano como ser-em-el-mundo y ser-con-el-outro. Discute la insuficiência del concepto de la soledad patológica destacando los límites de este enfoque con respecto a la comprensión existencial del fenómeno de la soledad para entenderla como una experiencia existencial originaria y se instala en el horizonte de nuestra temporalidad, a partir de los existenciales do ser-conel-otro y el tono afectivo de angustia. Enfatizamos la cercanía entre la angustia y la soledad como el aislamiento existencial, y la importancia de establecer con la angustia y la soledad que Heidegger llamará pensamiento meditative para la apertura de nuevos significados que permiten el rescate de la responsabilidad pornuestros proyectos existenciales, singularización y nuestra libertad.
\end{abstract}

Palavras-Clave: soledad, psicologia, analítica existencial, Heidegger.

\title{
Introdução
}

Dentre os fenômenos que se revelam no horizonte das relações sociais e afetivas na contemporaneidade, a solidão sobressai como uma experiência que nos chama a atenção de modo diferenciado. Em suas inúmeras formas ela se faz presente ora como sintoma, ora como um sentimento que deve ser estritamente aplacado ou mesmo repensado em sua relação direta com a sociedade. Como reflete Sponville (2001) em O amor a solidão, a sociedade não é o contrário da solidão e vice-versa, pois na maioria das vezes "estamos ao mesmo tempo sós e juntos". Ou seja, ao mesmo tempo que as interações sociais nos agregam, juntando-nos uns aos outros, ela nos dá o testemunho da solidão como um fenômeno mais flagrante, permitindo em grande escala o registro do anonimato ou mesmo de angústias que, por vezes, nos desestabilizam.

O propósito do artigo é problematizar o caráter patológico conferido à solidão - enquanto uma experiência significativa da sociedade contemporânea -, posto que a compreensão desse polissêmico fenômeno revela outros sentidos e significados. Parte-se do fato de 
que nas relações cotidianas a solidão é privilegiada em sua significação patológica, e que tal estreitamento hermenêutico possibilita um fechamento de horizontes no modo como esse fenômeno pode ser compreendido, sobretudo em sua perspectiva existencial. Assim, é geralmente percebida como um estadosentimento indesejável, desvelado como uma experiência de sofrimento, e que passa a ser apropriada pelo discurso psiquiátrico enquanto sintoma que deve ser estritamente aplacado.

É preciso então compreender como é possível na atualidade a construção de um discurso normatizador que arbitra sobre os diversos comportamentos sociais de modo a considerar determinadas condutas como perigosas à sociedade e por isso passíveis de intervenção e controle. É esse saber-poder que se estende até os dias atuais na catalogação não só do patológico, mas dos comportamentos em geral.

A problematização do caráter patológico da solidão, costumeiramente destacado, justifica-se como condição de possibilidade de assinalar os limites de sua significação redimensionando sua abordagem em seu sentido ontológico; o que nos conduz a pensar a solidão como constitutiva do nosso modo de ser, de nossa existência. Nesse propósito, toma-se como referência o pensamento de Heidegger (1927/2006), não apenas considerando suas reflexões específicas sobre essa temática, mas sua advertência quanto ao fato de que existimos de um modo hermenêutico, isto é, compreendendo e interpretando tudo aquilo com que nos relacionamos. Assim, as interpretações se dão a partir do mundo enquanto um conjunto de sentidos sedimentados, expressos pela linguagem, repassados pela cultura, mas submetidos ao pensar. Desse modo, a reflexão sobre a solidão nos convoca a compreendê-la como uma experiência que integra a nossa existência; não como um acontecimento patológico que compromete a saúde, mas como experiência de busca de sentido sobre o modo como somos no mundo e com os outros.

\section{Solidão e alguns sentidos de sua polissemia}

Partindo de sua origem etimológica, o termo solidão deriva da palavra latina "solus", que, segundo Cunha (2001), significa estar só, solitário, desacompanhado e único. O dicionário eletrônico Houaiss (2009) também destaca como raiz etimológica desse termo a expressão "solitūdo", significando desamparo, abandono e retiro. De "solus" deriva a palavra "desolo" e o verbo desolar, que se define como deixar só, despovoar, devastar, assolar, destruir.

Conforme Tamayo e Pinheiro (1984), uma definição e conceituação da solidão deve considerar os seguintes aspectos: sentimento de isolamento; sentimento indesejado e desagradável; falta de sentido e 
significado na vida e deficiência nos relacionamentos. Tais pesquisadoras apontam que na solidão há um sentimento de alienação da pessoa em relação às outras. Daí por que o solitário costuma se questionar acerca do sentido de sua existência quando esse sentimento é despertado com frequência.

Até o momento, tal definição de solidão enfoca a angústia, as dificuldades pessoais e o sofrimento que ela desencadeia, mas sem necessariamente apontar para o patológico. Entretanto, em uma perspectiva de pesquisa fenomenológica transcultural das correlações entre solidão e depressão, Moreira e Callou (2006) mostram que a solidão, para os seus entrevistados, é intencionada como sinônimo de isolamento, bem como a experiência de morar só e a ausência de amigos são aspectos relacionados à depressão. Ademais, a pesquisa também enfatiza a solidão associada à vida a dois, significado esse que emerge no processo de vivência de viúvas, de homens separados e na relação de mulheres com maridos ausentes. Logo, o sentido apresentado está ligado à falta de relacionamentos sociais como possível etiologia e consequência da solidão. Todavia, o que o presente artigo pretende discutir ultrapassa esse alcance, na medida em que contempla aquilo que constitui a solidão enquanto anterioridade, enquanto modo de ser, isto é aquilo que perfaz a sua condição existencial e ontológica.

Não se trata aqui de afirmar que os modos patológicos de solidão não são modos possíveis de interpretação, mas de problematizá-la segundo o primado filosófico de Martin Heidegger, expresso a partir de Ser e Tempo (1927/2006). Para este autor nossa essência é nossa própria existência, e existindo já existimos com o outro; coexistimos, e enquanto tal já estamos lançados em um mundo enquanto totalidades de significações históricas e socialmente sedimentadas. Portanto, não podemos nos pensar apartados do mundo e das outras pessoas, pois o mundo e o outro nos constitui em nosso existir e nos é indissociável.

Daí por que a solidão não pode ser pensada independente e anterior à existência, pois, pelo contrário, a solidão é necessariamente uma experiência daquele que existe e que revela o seu modo de existir. Eis o que sustenta a afirmação de que ela, em si, não se constitui um fenômeno patológico. Mas vejamos, a seguir, as perspectivas diferenciadas dessas abordagens.

\section{A solidão enquanto patologia}

Conforme destacam Moreira e Callou (2006), ocorre no senso-comum uma associação entre solidão e depressão. Geralmente a solidão em sua pesquisa é vista pelos seus entrevistados ou como consequência da depressão ou como sendo fator etiológico desta. Embora a solidão 
possa se associar à depressão como uma possibilidade de interpretação de nossos sofrimentos, é preciso destacar como toda uma série de veiculações midiáticas e mercadológicas voltadas ao consumo, sucesso e hedonismo, assim como também o discurso instituído do saber médico (Dantas, 2015) acabam por promover um fechamento de possibilidades hermenêuticas sobre tal fenômeno existencial. Dentro desses limites, o "solitário" ou o "depressivo" interpreta as suas vivências e a si mesmo apropriando-se de sua experiência como patologia.

Mas o que justificaria ou mesmo legitima a primazia dessa abordagem compreensiva da solidão? Que horizonte histórico permite que o fenômeno da solidão ou mesmo da tristeza sejam desvelados em sua diretiva patológica? É possível pensar tal conjuntura a partir do processo de psiquiatrização da vida por meio da razão técnicocientífica e de um modelo biomédico de saúde. Vale lembrar que, de acordo com Foucault (1961/1978), a partir da criação dos estados modernos, a Psiquiatria e os manicômios passam a funcionar como um mecanismo de controle social das sociedades disciplinares.

Segundo Dalgalarrondo (2008), sendo a semiologia a ciência dos signos, a semiologia psicopatológica corresponde ao estudo dos sinais e sintomas dos transtornos mentais. Neste processo de identificação de sinais psicopatológicos, os signos apresentam a dimensão tanto de indicador como de símbolo. Como índice apontam para uma disfunção localizada em algum ponto do organismo ou do aparelho psíquico; há aqui uma relação de contiguidade, onde, por exemplo, a febre corresponde a uma infecção.

Nessa linha de raciocínio, Foucault (1963/2011), aponta que os signos seriam códigos a serem decifrados como uma linguagem natural pelos médicos a partir de seu olhar. Este olhar não apenas sabe da doença, mas a rege e decide sobre ela. Decide não a partir de si, mas da instituição do saber médico de onde se é possível acessar sem ocultação a realidade última da doença por meio de seus significantes. Tal procedimento evidencia uma divisão entre os fenômenos que significam saúde e aqueles que significam doença, sendo estes últimos muitas vezes confundidos, enquanto quadro, com os seus sintomas. Por tal oposição o sintoma deixa de ser passivo e passa a ser significante de doença, ou seja, o sintoma é a doença em sua totalidade, uma vez que a doença seria uma coleção de sintomas. Nessa perspectiva de compreensão, a solidão, enquanto fenômeno aqui abordado, e o isolamento passam a ser signo de um quadro nosológico de uma síndrome ou patologia. Tal afirmativa pode ser constatada a partir de uma pesquisa em um banco de dados em que consta o DSM-IV (Psiqweb, 2014). Os descritores solidão e isolamento retornaram 15 diferentes quadros sindrômicos.

Foucault (1963/2011) critica a forma como a cientificidade, ou melhor, a mitificação da ciência se verifica, de modo que o médico, 
pautado no discurso da instituição médica, opera como aquele que detém o conhecimento onipotente e inefável da saúde e da doença. Segundo este pensador francês, a incerteza que imperava na clínica médica no século XVIII começa, a partir desse mesmo século, a remediar a incerteza a partir da "soma de graus de certeza isoláveis e suscetíveis de um cálculo rigoroso" (Foucault, 1963/2011, p.106).

Com isso, a probabilidade vai ganhando uma maior força na catalogação de um domínio de acontecimentos clínicos. Todas as variações se anulam na configuração geral, pois fazem parte do próprio domínio da probabilidade. Ora, se o signo já é a própria doença em sua presença, de modo que alguns signos são mais patológicos que outros, e se existe uma "curva normal" que busca uma generalização das vivências coletivas no âmbito biológico, e que por meio da psiquiatria também se manifestam no âmbito do social, como não pensar a solidão em si como patológica?

Na sua obra Os anormais, Foucault (1975/2001) aponta como a psiquiatria e outras formas de saber-poder foram utilizadas na construção do estado moderno para a prevenção de perigos que pudessem atingir a população a partir de um conjunto de conhecimentos que faziam parte da higiene pública. Assim, a psiquiatria (Foucault, 1975/2001, p. 149) não só funcionaria como um dispositivo de higiene pública, mas também enquanto busca da eventual cura da doença mental como meio de "precaução social absolutamente necessária, para se evitar um certo número de perigos fundamentais decorrentes da existência mesmo da loucura". Entretanto, conforme Foucault (1975/2001) prossegue na apresentação dos seus argumentos, a psiquiatria não se restringe à doença mental, mas abarca também o anormal, o degenerado, que não estando doente, pois não tem cura, é uma espécie de monstruosidade e degradação da natureza humana. A psiquiatria se insere aqui em um âmbito não só patológico-normativo, mas também médico-jurídico. Era preciso classificar os comportamentos perigosos ao estado, propiciadores da desordem e da imoralidade.

Conforme Canguilhem (1966/2009), mais do que a opinião dos médicos, subsiste toda uma conjuntura social que determina aquilo que se chama "doença". A patologia e o normal tornam-se assim valores virtuais que têm sentido dentro de uma determinada sociedade e cultura. Estar doente significa ser indesejado, desvalorizado socialmente ou de alguma maneira se tornar evitável. Aponta também que, sobremaneira, os valores desejados em nossos tempos são uma vida longa, capacidade de reprodução, capacidade de trabalho físico, ausência de dor, um estado onde se sentiria o corpo o mínimo possível e o fato de existir se tornasse o mais agradável possível.

Qual é então o contexto que permite pensar a saúde como esse estado hedônico e paradisíaco descrito por Canguilhem? Heidegger 
(1954/2007) aponta em seu texto $A$ questão da técnica que a maneira como 0 homem se relaciona com a natureza na contemporaneidade se apresenta de modo totalmente diverso a períodos anteriores da história. Tudo passa a ser visto sobre a ótica de um desvelamento científico técnico onde a natureza se torna recurso a ser explorado, armazenado, reutilizado e disponível para consumo. A técnica em sua essência não seria apenas um meio para um fim, mas um modo de desvelamento da verdade e um horizonte hermenêutico que é pano de fundo para o desvelamento dos entes.

Nesse sentido o pensamento calculador, fundamento do controle e previsibilidade científicos, se faria presente também no modo como lidamos com as nossas experiências existenciais. Para Dantas, Sá e Carreteiro (2009), tal horizonte técnico, aliado ao fenômeno das mídias, da medicalização, do mito da imortalidade e sucesso absolutos, acabam por ofuscar a possibilidade de lidar de uma maneira "não-patologizante" com as imprevisibilidades da vida, com a morte, com a angústia, com o fracasso e todas as demais experiências que expressam nossa finitude, e ao mesmo tempo revelam aquilo que há de mais próprio e característico do nosso modo de existir.

Tal ofuscamento permitiria uma atitude de controle ilusório do nosso devir e do nosso projeto existencial. Assim, ao ser confrontado com a quebra de tais seguranças, há, para os autores supracitados, a possibilidade de irrupção de modos patologizados de lidar com a angústia, a saber, as fobias, depressões, e demais psicopatologias. Dado o nivelamento dessa abordagem, e também considerando a proximidade da solidão à tonalidade afetiva da angústia enfatiza-se a necessidade de pensarmos tal fenômeno a partir de uma leitura ontológica, com vistas a desvelar outras possibilidades de sentido que escapam ao horizonte técnico-calculante.

\section{A solidão sob a perspectiva da analítica existencial de Heidegger}

A pergunta pelo "ser" será o norte do percurso intelectual de Heidegger em Ser e Tempo (1927/2006). Sua primeira afirmação positiva é a de que já possuímos desde sempre uma compreensão do ser, quando dizemos, por exemplo, que "o céu é azul". Entretanto, conforme o filósofo, a história do pensamento ocidental testemunhou o "esquecimento do ser", o compreendendo ora como sinônimo de ente, ora como sinônimo de uma presença constante, no sentido de uma substancialidade atemporal.

Ainda assim, é essa noção de familiaridade que temos com o ser que Heidegger (1927/2006) toma como ponto de partida para refletir o ente em sua relação com o ser. Este ente somos nós, cuja 
denominação conceitual é o ser-aí (Dasein). Na compreensão mediana e banal do nosso ser, Heidegger então atenta ao questionamento sobre o sentido do ser, o que instaura a necessidade de uma analítica da existência em que o ser-aí é pensado em sua radicalidade ôntico-ontológica e enquanto projeção existencial no horizonte de sua temporalidade (Zeitlichkeit).

A analítica existencial reflete então a estrutura ontológica do ser-aí. Ou seja, as estruturas ontológicas (do ser de todos os ser-aí) permitem que onticamente, em um nível concreto e individual, a nossa condição existenciária (Existenziell) se dê dessa maneira e não de outra. Atentar a essa questão é importante na medida em que, de acordo com Heidegger (1927/2006), essa explicitação poderia ajudar na colocação da pergunta acerca do ser em geral. Eis a condição de possibilidade para discutir-se sobre quem é o ser-aí que somos nós, ou o melhor, qual é o ser do ser-aí, e assim assegurar uma maior clareza à pergunta pelo sentido do ser.

De acordo com Heidegger (1927/2006) o ser-aí possui um primado ôntico-ontológico, ou seja, é um ente que possui uma relação privilegiada com o ser, na medida em que compreende a si e aos entes. Este ser que ele é nunca está totalmente dado, mas sempre lançado em um contexto histórico factual, sempre incompleto e nunca total e aprioristicamente delimitado em suas possibilidades. Não há aqui, então, um conteúdo coisificador e entificador do ser-aí; ao contrário, ele já sempre possui o seu ser como seu. Dito de outra maneira, ao questionar a si mesmo o ser-aí não está visando o seu ente, mas o seu ser, seus modos de ser e suas possibilidades de ser.

\subsection{Desvelando o fenômeno da solidão ontológica sob a forma de tonalidades afetivas}

Abordar a solidão em sua acepção ontológica pressupõe a necessidade do conhecimento de alguns existenciais, imprescindíveis à sua compreensão. Os existenciais são os elementos que constituem essa estrutura ontológica, porém não como categorias (cor, peso, altura), uma vez que estas se aplicariam apenas a objetos, e não à extensão dos possíveis modos de ser. Não há como existir sem que eles (os existenciais) já estejam dados enquanto sempre possíveis. Da mesma maneira, o fenômeno da solidão não se remete especificamente à presença ou à falta de alguém. Para nos sentirmos sós não é necessário que estejamos sem uma outra pessoa ao nosso lado, ela pode se dar em meio a uma multidão, ou mesmo em meio a uma relação íntima. Se a solidão estivesse no âmbito do puramente categorial, ela se esvairia imediatamente com a presença de qualquer outro.

Assim a compreensão (Verstehen) do ser que o ser-aí possui já se constitui como um existencial. Em maior ou menor grau existimos 
compreendendo o mundo em uma relação que não é, numa primeira aproximação, uma relação reflexiva com aquilo que compreendemos. Geralmente o que compreendemos se dá a partir de todo um legado histórico de sentidos sedimentados que cria uma rede de remissões. Daí que os instrumentos (Zeug) e os entes manuais (Zuhandenheit) geralmente são ser-para, tem uma determinada função e se remetem um ao outro. Podemos citar, por exemplo, o lápis que se remete a folha e que por sua consequência se remetem ao apoio para escrever, e que por fim se remetem ao ser-aí.

Fato é que toda essa rede de remissões, como também as possibilidades do ser-aí, na medida em que se lançam em seu projeto existencial precisam de um espaço correlato onde essa projeção se dá. Assim o ser-aí é ser-no-mundo (In-der-welt-sein). Esse ser-nomundo não é aqui entendido como uma relação de encaixe no mundo, mas como uma relação de familiaridade. Para o pensador germano, a relação com o mundo ocorre num engajamento préreflexivo. Esse mundo que está aí diante de nós não é ente nem receptáculo de objetos, mas o que torna os entes a nós acessíveis. No mundo, na familiaridade com este e na sua relação co-originária é que os entes podem vir ao encontro do ser-aí; é nessa familiaridade com o mundo que os entes se revelam, podem ser desvelados e que o homem habita. Portanto, é pela própria característica ontológica de compreensão que o ser-aí descerra o mundo enquanto o espaço onde se revelam os entes, ou seja, os objetos em geral.

Ao já estar desde sempre no mundo, nos encontramos não só junto às coisas, como também junto aos outros ser-aí. O mundo para Heidegger (1927/2006) toma uma estruturação mais complexa na medida em que é também mundo compartilhado com o outro; serno-mundo é ser com o outro. Trata-se então, de uma interação e possibilidade de encontro junto ao outro no mundo. Uma vez que existir é existir com o outro no mundo, somos ser-com (Mitsein), e esse outro garante um significado amplo sobre 0 nosso reconhecimento enquanto ser-no-mundo. Na medida em que são cooriginários, o ser-aí se constitui também a partir dos outros, das visões que o outro tem, dos modos como o outro é, e principalmente dos modos como o outro lhe toma a tutela existencial e lhe posiciona em um determinado lugar.

Segundo Heidegger, esses "outros" ser-aí que eu encontro são os outros dos quais na maioria das vezes eu não consigo me diferenciar. O "com" de ser-com não aponta para um ente dado em conjunto com o outro; o "com" é, na verdade, um existencial, parte da estrutura ontológica do ser-aí. Dito de outra maneira, é o outro ou os "outros" num sentido genérico que também são co-originários que podem se tornar referência, e não um outro específico.

Ser-com não é algo que se dá apenas quando um outro qualquer está ao meu lado ou próximo a mim como uma propriedade que seria 
reinserida sempre que um outro assim se fizesse presente. Em suas palavras, para Heidegger (1926/2006, p.177) "o ser-com determina existencialmente a presença, mesmo quando um outro não é, de fato, dado ou percebido. Mesmo o estar só da presença é ser-com no mundo. Somente num ser-com e para um ser-com que o outro pode faltar". Daí por que o sentir-se, o não perceber, o não ser tocado pelo outro se constituem como modos deficientes de ser-com, que não prova a ausência do ser-com, pelo contrário revela que estamos sós porque há ser-com.

Logo, é só para um ser-aí que reconhece o outro como outro ser-aí que alguém pode faltar. Assim, nós podemos estar em uma sala sem nenhuma outra pessoa, mas só podemos constatar que não há ninguém por sermos "ser-com". Do mesmo modo podemos passar ao lado de alguém e nem o perceber, mas isso não retira o fato de que somos ser-com. Como já diria Boss (1976), solidão e comunidade não se excluem, mas pelo contrário a comunidade é a própria condição para que se dê a solidão. Assim, a solidão exige a existência de um outro, um direcionamento para a alteridade.

Nesse sentido sobressai como relevante a discussão desenvolvida por Lima (2012) ao fazer uma análise das nomenclaturas usadas por Heidegger para pensar a solidão. Dentre elas está a solidão enquanto Alleinsein que é a solidão pautada a partir do fato de o ser-aí ser também ser-com, e enquanto uma solidão "perceptiva". Aqui o termo "perceptiva" se remete ao fato de que mesmo que se escolha viver uma vida de solidão, sempre se estará remetido a um outro, uma vez que originariamente esse outro me constitui, e, constituindo-me, o percebo em sua falta. Tal argumento destaca a compreensão do sercom representando um componente transcendental (universal) do ser-aí, ou seja, intrínseco, indispensável e onipresente em relação à própria apresentação do mundo como tal.

Em suas análises, Lima (2012) aponta ao menos dois significados para a solidão enquanto Alleinsein: a primeira é a do Alleinsein enquanto solidão perceptiva, conforme já explanado, que é onde não há perante mim um outro percepcionado. Essa solidão é a solidão que se usa comumente na linguagem e indica que necessariamente não há ninguém ao meu lado. Entretanto, em sua segunda forma, esse alguém que deveria estar ao meu lado geralmente é identificado como um alguém que é um "outro como nós". Assim, a solidão enquanto Allensein está ligada à percepção da ausência de um outro que é como nós. Uma vez que se encontra um outro que não é "como nós", ele se mostra ao ser-aí a partir dos modos da indiferença e da estranheza, que são modos deficientes de ser-com. Quando Heidegger (1927/2006) apresenta os modos deficientes de ser-com e quando ocorre a noção de que esse outro é um outro como eu, se dá um entendimento de comunidade. $\mathrm{Na}$ ideia de comunidade fica 
implícita a noção de que existe um sentido comum entre um ser-aí e outro, e que assim permite a compreensão do outro como um eu.

Outro existencial que nos permite acessar a solidão em seu caráter ontológico são as tonalidades afetivas, mais especificamente a tonalidade afetiva da angústia. Se, conforme já explicitamos, a concepção ontológica do ente que pergunta pelo seu ser, corresponde ao ser-aí, o que significa exatamente este aí? Podemos pensar, a partir de Heidegger (1987/2001a), que o aí revela a própria abertura ontológica da espacialidade que permite enunciar o aqui e o lá. Assim, o aí expressa uma abertura que o ser-aí possui em seu movimento existencial de compreensão do mundo, dos entes, de si e dos outros. É no campo aberto do aí que o ser do ser-aí está em jogo. Para Heidegger (1927/2006), os três modos constitutivos do aí do ser-aí são o compreender (Verstehen), as tonalidades afetivas (Stimmungen) e a fala (Rede). Tanto a compreensão quanto as tonalidades afetivas são modos de ser que se determinam pela fala. Entretanto, convém deixar claro o quanto as tonalidades afetivas são indissociáveis da compreensão, e na verdade se dão enquanto uma totalidade. Faz-se uma diferenciação apenas de maneira a apontar esses momentos constitutivos.

Aqui explicitaremos as tonalidades afetivas, que possuem esse nome enquanto uma designação de estrutura ontológica, mas que onticamente são conhecidas por humor, ou como estar afinado em um humor. O fenomenólogo aponta que o humor revela "como alguém está e se torna", e esse "como alguém está" se remete ao seu aí, factual e mundano. A afinação do humor, que é possibilitada ontologicamente pelas tonalidades afetivas, acaba por demonstrar que o ser-aí está entregue ao humor enquanto um ente "cuja responsabilidade o ser-aí se entregou em seu ser e que, existindo, ela tem de ser" (Heidegger, 2006, p. 193). Em outras palavras, o humor não é tematicamente refletido pelo ser-aí e na maioria das situações ônticas (concretas e individuais) o ser-aí já se esquivou dessa tematização e já está afinado em um determinado humor.

Necessário se faz compreender que para Heidegger (1927/2006) humor não se entende a partir de uma localização interna que se dá na consciência. O ser-aí ao existir já está sempre lançado para além de si mesmo, junto às coisas com que se relaciona. Isso implica dizer que não faz sentido aqui falar de uma substância (homem) que entra em contato com outra (mundo), pelo contrário, o ser-aí é ser-nomundo e ser-com, constitutivamente indissociável desses elementos. Para o filósofo, apesar de haver um si mesmo (man selbst) que se diferencia dos outros, esse si mesmo não é uma subjetividade, não fazendo sentido dizer que há um mundo fora do ser-aí, uma vez que só ele habita esse mundo e desvela o horizonte onde as coisas se manifestam. 
Para explicitar como se dá o despertar de uma tonalidade afetiva, Heidegger (1983/2011) lança mão do exemplo da tonalidade afetiva da tristeza. Exemplifica uma situação onde alguém está perceptivelmente triste, e não muda sua forma prática de lidar conosco (diz as mesmas coisas, age da mesma maneira e etc.). Há nesta situação a percepção de que tudo está do mesmo jeito e ao mesmo tempo diverso. O que muda nesse exemplo não é o que se fala e diz, mas como o ser-aí está. Mas convém esclarecer que este "como que se modifica" não pertence a uma consequência no sentido de uma relação causa e efeito. Na tristeza esse "como" pertence ao modo de ser triste. E como é este modo de ser triste? Neste momento o ser-aí se torna inacessível. Nas palavras de Heidegger (1983/2011, p.86), "o modo como podemos estar com ele e o modo como ele está conosco é um modo diverso". Logo, o que irá mudar, em todas as tonalidades afetivas, é o nosso modo de ser-com. Cada tonalidade nos traz para o interior dela sem que necessariamente estejamos afetados.

No pensamento de Heidegger (1927/2006; 1987/2001a; 1983/2011), algumas tonalidades afetivas acabam por possuir uma maior ênfase que as demais, exatamente por revelar o ser-aí para si mesmo naquilo que ele possui de mais fundamental, que é o fato de que sendo é o seu próprio poder-ser. Sendo, também possui uma responsabilidade pelo seu ser e é sua própria singularidade. O ser-aí não possui aqui uma substancialidade, sendo definido mais por uma negatividade, entendida aqui não no sentido moral, mas da ausência de um ente ou categoria que positivamente diga da totalidade de suas possibilidades. Essas tonalidades são a angústia, o medo e 0 tédio.

Em função de analisarmos o fenômeno da solidão em sua diretiva ontológica, deter-nos-emos nesse artigo apenas na tonalidade afetiva da angústia. Esta permite retirar o ser-aí de uma posição de impropriedade que geralmente se encontra. Na impropriedade o seraí acaba por enxergar a si mesmo como um ente, acabado e completo não explicitando para si o seu poder-ser. Outra possibilidade é a de que o ser-aí se oriente a partir das indicações do discurso público e do impessoal. Aqui acabamos nos perdendo naquilo que "os outros fazem", "que os outros dizem", e "que os outros pensam", de modo que a responsabilidade por nossas escolhas existenciais sejam eclipsadas naquilo que "os outros", em um sentido genérico, escolhem.

$\mathrm{Na}$ angústia aquilo com o que e pelo que o ser-aí se angustia é o próprio ser-no-mundo, uma vez que não há um ente específico que seja captado como angustiante como ocorre, por exemplo, na tonalidade afetiva do medo. Heidegger (1927/2006, p.253) pensa a angústia exatamente na esteira do pensamento de uma captação do nada (das Nichts), pois, "fenomenalmente, a impertinência do nada e 
do em lugar nenhum significa que a angústia se angustia com o mundo como tal. A total insignificância que se anuncia no nada e no em lugar nenhum não significa ausência de mundo".

A angústia se angustia com o mundo como ele é aberto, não como ausência total de qualquer coisa, mas como insignificância. A relação de ser-no-mundo não é rompida, ela está, por assim dizer, alterada e o ente intramundano não possui em um nível ôntico qualquer significado. Portanto, há um estreitamento de sentidos em relação a nós mesmos e em relação a tudo que achávamos conhecer.

Pode-se dizer que a angústia rompe com a evidência que tínhamos de nós mesmos. Ora, essa evidência de nós mesmos é construída a partir de uma entificação de nós mesmos. Por exemplo, a partir de uma identificação com uma determinada profissão, status social, papel familiar e etc. Para Heidegger (1927/2006), é a partir dos próprios entes que na medianidade do dia a dia nos compreendemos. Quando uma dessas esferas entra em declínio, ou seja, quando perdemos a possibilidade de nos entender a partir desses espaços que nos permitem habitar o mundo, de ter uma familiaridade com ele, nos sentimos angustiados.

Entretanto, mesmo com essa perda pessoal daquilo com que alguém se identifica, pode ainda haver uma reconstrução de si. O que mostra que aquilo que propriamente somos não são essas identificações, mas sim o nosso próprio poder-ser que está em jogo. Caso contrário, a perda dessas identificações resultaria em uma aniquilação instantânea, ou mesmo na morte. Aqui também o mundo é desvelado como mundo, e não mais a partir dos seus entes que o compõem. Ele é tematizado em sua própria abertura, enquanto um mundo que não está totalmente constituído, mas que se constitui na medida em que o ser-aí o constitui na sua relação com os outros e com o próprio mundo.

Nesse sentido, Heidegger (1927/2006, p. 254) reflete sobre aquilo com o qual a angústia se angustia; ela se angustia não com um ente qualquer, mas "se angustia pelo próprio ser no mundo". Ora, mas que relação há entre o então exposto e a solidão enquanto isolamento existencial? Aqui a totalidade da relação do ser-aí com o mundo se suspende. Como o mundo não é somente um mundo onde se encontra entes, mas também um mundo compartilhado, e onde eu encontro o outro, o significado que esse outro possa ter para mim é também suspenso. Nas palavras do filósofo germano, "o mundo não é mais capaz de oferecer alguma coisa, nem sequer a co-presença dos outros" (Heidegger, 1927/2006, p. 254).

É exatamente esse o sentido que Lima (2012) também nos aponta acerca da solidão, a partir do pensamento de Heidegger, enquanto isolamento existencial (Existenziale Vereinzelung). E por meio da angústia (e também da consciência da possibilidade de morte própria) que o ser-aí é restituído à tensão existencial que o diferencia 
em relação aos demais. Essa tensão existencial se dá na medida em que o ser-aí, enquanto sendo o seu próprio poder-ser, estando em jogo, está sempre em causa para si mesmo. O estar em causa para si mesmo aponta para aquilo que é uma possibilidade - mas que o seraí ainda não é - que é a totalidade de suas possibilidades. Como essa restituição se processa? Inicialmente é preciso apontar que na restituição dessa tensão existencial nos fica claro que somos responsáveis pelo nosso ser, e que as escolhas que o outro faz não necessariamente nos dizem respeito, na medida em que só eu posso me escolher.

$\mathrm{Na}$ angústia não é somente o mundo, como também o outro que perde o sentido. Nesse processo o ser-aí se torna indiferente a tudo aquilo que aparece. A indiferença aponta para uma desconcertante tensão e sentimento de não familiaridade (Umheilich), uma vez que o seu ser, enquanto poder-ser, não é tomado por um outro que lhe daria segurança de suas ações e escolhas. A angústia se expressa então por meio de um clamor da consciência visando uma relação de maior propriedade, ou seja, de realização das nossas possibilidades singulares e de que escolhamos mais a partir de nós mesmos do que dos sentidos sedimentados pelo mundo. A singularização é assim um processo de modulação que não rompe totalmente com a impessoalidade, visto que a propriedade e impropriedade sempre estarem em jogo no ser-aí, explicitando o ser-aí como seu próprio poder ser.

Entretanto, sobressai no universo hermenêutico atual o fato de que toda a existência e a conjuntura da sociedade se encontram sob os ditames de um horizonte pautado pela medicalização. Para Dantas (2015) tal fenômeno se torna mais expressivo a partir da inserção dos psicofármacos no mercado de consumo. O horizonte hermenêutico técnico-calculante da contemporaneidade interpreta o ser-aí como individuo, subjetividade encapsulada e neuroquimicamente regulada sobre os preceitos da medicina. Esta tem como modelo imperante o acesso ao homem a partir do olhar biomédico e tecnológico, onde o corpo é passível de mecanização, controle, ou mesmo, como nos apresenta Sibilia (2003), de upgrade.

Assim a medicalização sufoca e encobre os fenômenos próprios do existir, negando elementos próprios do modo como se processa a vida e recaindo no que Dantas (2015) irá chamar de uma narcotização e entorpecimento da vida e dos sofrimentos. Há inclusive a possibilidade de que tal negação acabe por restringir as possibilidades de ressignificação da existência, se tornando também fonte de sofrimento. Tal ressignificação ocorre por via da responsabilização pessoal do projeto existencial singular, o que só se dá frente a concepção da finitude em um sentido próprio, ou seja, na constatação de que um dia ser irá morrer e de que a existência é plena de imprevistos e tragicidades. 
Isolamento existencial enquanto solidão, para Heidegger (1927/2006), não está, por assim dizer, apontando a solidão enquanto um estado que necessariamente leve o homem a adoecer. Pelo contrário, não é fácil a desconfirmação de si ou a desoneração das opiniões já construídas e legadas; entretanto esse fenômeno existencial não implica necessariamente uma doença. Isso se dá porque o ser-aí é, simplesmente, angústia. A angústia constitui seu ser, e frente à impossibilidade de ter em alguém, ou algo em que se apoiar por meio da impessoalidade, o ser-aí também está só. Ele tem que escolher por si só qual o seu caminho e onde pode novamente habitar, uma vez que a solidão, enquanto isolamento existencial, é desoladora no sentido de quebra de familiaridade com o mundo, mas é constitutiva enquanto possibilidade já sempre dada e reiterada.

Assim, antes de uma solução rápida e mágica pela qual somos interpelados dentro do horizonte de desvelamento técnico, Heidegger (1959/2001b) nos apresenta o modo de pensar que irá intitular de pensamento meditante. Portanto, antes de nos situarmos no horizonte imediato e veloz do desvelamento da natureza enquanto recurso propiciado pelo pensamento técnico calculador, convém atualizarmos a pergunta pelo sentido das coisas como forma de nos mantermos no próprio horizonte de abertura do ser-aí. E então nos mantermos frente à estranheza e ao desalojamento da experiência do ser-aí, renunciando ao controle dos entes para que estes se desvelem por si mesmos.

\section{Considerações Finais}

A partir do raciocínio aqui desenvolvido pode-se perceber o quanto o discurso biomédico pode tornar elementos constitutivos de nossa existência como patológicos. Geralmente os aspectos desagradáveis do existir devem ser estritamente extintos antes que frente a eles exercitemos o que Heidegger (1927/2006) denomina como experiência de demora diante daquilo que se revela para nós. Tal forma de pensar busca para além das sedimentações históricas a compreensão do fenômeno a partir dele mesmo. Assim, nos foi retirado, a partir das classificações e manuais do psíquico, um modo nosso de compreender as experiências que possuímos.

A angústia por si só não implica necessariamente em uma experiência agradável e hedônica, e nem se constitui como preocupação desse trabalho uma ode a esta, ou recomendação de que devamos a todo momento nos angustiar. Antes disso devemos apontar que a angústia é importante, pois, revela a própria liberdade do ser-aí, e a possibilidade de que em meio a angústia, e em meio a sua finitude, o ser-aí possa escolher a si mesmo a partir de seus próprios referenciais e daquilo que lhe é significativo. 
Cabe lembrar que a possibilidade de que a angústia nos tome pode ser desencadeada pela mais banal das possibilidades, e o mesmo podemos dizer da solidão. Assim, o homem é sempre necessitado de cuidado (Sorge), uma vez que pode perder-se frente à incapacidade de lidar com sua própria negatividade e liberdade (Heidegger, 1987/2001a). E aqui, em meio a essa possibilidade de perder-se e de não conseguir lidar consigo e com sua liberdade que pode se instituir uma patologia, que compreendida em uma perspectiva existencial, como enunciado nos Seminários de Zollikon, como uma perda da liberdade e limitação das possibilidades de viver.

Entretanto, por mais que possamos dizer que a patologia pode se constituir, é incorreto dizer que a solidão e a angústia são condições necessárias e suficientes para desencadear uma doença. Antes disso, podem ser apropriadas inclusive no sentido de uma relação saudável para consigo mesmo. Uma relação que delimita para si seus próprios contornos diferenciando-se dos demais. A possibilidade de escolher aquilo que nos é mais significativo nos desvinculando do que "devemos" ser em função dos outros. Ou mesmo a possibilidade de nos revermos, de mantermos vivo o próprio movimento que é o existir, de maneira a não nos confundirmos com um objeto.

Para tal, se faz necessário sustentar a experiência de angústia por meio de uma resposta que possibilite uma maior apropriação de nosso projeto existencial singular, antes de tamponá-la ou buscar uma solução mágica e imediata unicamente por via do entorpecimento e da não aceitação da vida em suas facetas mais trágicas. O pensamento meditante frente à angústia, na contramão do pensamento calculador, nos colocar frente a nós mesmos em uma atitude de aceitação das transformações inerentes ao nosso ser-aí, que é puro poder-ser. Apontamos aqui, por meio do pensamento meditante, para a possibilidade de um questionar a angústia em seu sentido e habita-la, demorar-se nela. Permitir que ela se apresente por si mesma e desvele novos sentidos e possibilidades em nosso existir.

A partir dos argumentos desenvolvidos na tessitura deste trabalho, pode-se desfazer a trama de sentidos elaborados no impessoal sobre os modos como lidamos com a angústia e a solidão. É possível então que não só a angústia, como também a solidão, se apresentem como experiências significativas e poderosas que permitam uma maior propriedade e ampliação de possibilidades existenciais. Enfatiza-se também a importância desses momentos ontológicos de nosso existir, apontando não para uma rápida medicalização e fuga de tais sentimentos. Ao contrário buscamos uma aproximação, um fazer morada e nos perguntar como faz o pensador germano em relação ao tédio (Heidegger, 1983/2011), o que quer a angústia e o que quer nossa solidão. Tais questionamentos permitem então desvencilhar-se de projetos existenciais prontos, legados pelas sedimentações que 
estão no mundo e que nos são anteriores, visando a responsabilidade por nosso projeto singular.

\section{Referências}

Abbagnano, N. (2007). Dicionário de Filosofia. São Paulo: Martins Fontes.

Boss, M. (1976). Solidão e comunidade. Revista da Associação Brasileira de Daseinsanalyse, 1(2), p. 25-45.

Canguilhem, G. (2009). O normal e o patológico. Rio de Janeiro: Forense Universitária (Obra original publicada em 1966).

Cunha, A. (2001) Dicionário etimológico da língua portuguesa. São Paulo: Nova Fronteira.

Dalgalarrondo, P. (2008). Psicopatologia e semiologia dos transtornos mentais. Porto Alegre: Artmed.

Dantas, J., Sá, R. N., Carreteiro, T. C. (2009). A patologização da angústia no mundo contemporâneo. Revista Arquivos Brasileiros de Psicologia, 61(2), p. 1-9.

Dantas, J. (2015). Medicalização e devir: impasses existenciais na era da técnica. Revista de Fenomenologia \& Psicologia, 3(1), p.1228.

Foucault, M. (1978). A história da loucura na idade clássica. São Paulo: Editora Perspectiva (Obra original publicada em 1961).

Foucault, M. (2011). O nascimento da clinica. Rio de Janeiro: Forense Universitária (Obra original publicada em 1963).

Foucault, M. (2001). Os anormais. São Paulo: Martins Fontes (Obra original publicada em 1975).

Heidegger, M. (2006). Ser e tempo. Petrópolis: Vozes / Bragança Paulista: Editora Universitária São Francisco (Obra original publicada em 1927).

Heidegger, M. (2007). A questão da técnica. Revista Scientia Studiae, 5(3), p. 375-389 (Obra original publicada em 1954).

Heidegger, M. (2001a). Seminários de Zollikon. Petrópolis: Vozes (Obra original publicada em 1987).

Heidegger, M. (2001b). Serenidade. Lisboa: Instituto Piaget (Obra original publicada em 1959).

Heidegger, M. (2011). Os princípios fundamentais da metafísica. Rio de Janeiro: Forense Universitária (Obra original publicada em 1983).

Houaiss, A. (2009). Novo dicionário Houaiss da língua portuguesa. Rio de Janeiro: Objetiva.

Lima, P. A. (2012). Heidegger e a fenomenologia da solidão humana. (Tese de Doutorado). Universidade Nova de Lisboa: Lisboa.

Moreira, V., Callou, V. (2006). Fenomenologia da solidão na depressão. Revista Mental, 4(7), p. 67-83. 
Psiqweb (2014). Classificações. Disponível em <http://www.psiqweb.med.br/site/?area=ES/Classificacoes $>$. Acesso em 15 de fev.2014.

Sibilia, P. (2003). O homem pós-orgânico: corpo, subjetividade e tecnologias digitais. Rio de Janeiro: Relumé Dumará.

Sponville, A. C. (2001). O amor à solidão. São Paulo: Martins Fontes. Tamayo, A., Pinheiro, A. (1984). Conceituação e definição de solidão. Revista de Psicologia da Universidade Federal do Ceará, Fortaleza, 2(1).

\section{Endereço para correspondência \\ Graco Silva Macedocouto}

Universidade Federal do Maranhão - UFMA

Rua Bartolomeu Gusmão, Quadra C, Casa 8, Ipase Alto, CEP 65062-070, São Luís MA, Brasil

Endereço eletrônico: gracomacedo@msn.com

\section{Almir Ferreira da Silva Junior}

Universidade Federal do Maranhão - UFMA

Av. Colares Moreira, 19, Torre Norte/802, Condomínio Versatille. Renascença II, CEP 65075-441, São Luís - MA, Brasil

Endereço eletrônico: alferjun@uol.com.br

Recebido em: 27/04/2015

Aceito em: 26/09/2016

\section{Notas}

* Mestre em Psicologia pelo PPGPSI (UFMA). Professor Substituto do Departamento de Psicologia (UFMA). Professor na Faculdade Pitágoras - São Luís.

** Professor Associado do Departamento de Filosofia. Doutor em Filosofia pela Universidade de São Paulo. Professor Permanente do Programa de Pós-graduação em Psicologia da Universidade Federal do Maranhão (linha de pesquisa: História, Epistemologia e fenômenos psicológicos). Professor permanente do Mestrado Profissional de Filosofia (em rede). Coordenador de Gestão do PIBID/UFMA. Área de Pesquisa: Filosofia contemporânea, Fenomenologia e Hermenêutica. 